\title{
Analytical Prediction of Inductances of Slotless Axial-Flux Permanent Magnet Synchronous Generator Using Quasi-3D Method
}

\author{
Qamaruzzaman, A. Pradikta, and P. A. Dahono \\ Electric Energy Conversion Research Laboratory \\ School of Electrical Engineering and Informatics, Institute of Technology Bandung \\ Jl. Ganesha No. 10, Bandung 40132 Indonesia \\ qamaruz@konversi.ee.itb.ac.id
}

\begin{abstract}
Generator inductances are important parameters to predetermine the generator performance. Synchronous inductance consists of magnetizing and leakage inductances. In this paper, an analytical approach is proposed to predict the inductances of slotless axial-flux permanent magnet synchronous generator. For this purpose, the generator is modeled by using quasi three-dimensional model. The calculated results are compared to the results of frequency response test.
\end{abstract}

Keywords: quasi-3D, synchronous generator, axial flux, inductance

\section{Introduction}

Development of modern wind turbine application in the world is triggered by success of Gedser wind turbine $(200 \mathrm{~kW})$ in 1957 which used three-horizontal-blade and grid connected. Later, power electronic research activities made wind turbine technology grows faster. Moreover, related to environmental issues, people need more electricity that is generated by green energy,

Until 2005, Indonesia has used 0.5 MW wind energy from the total potency 9.29 GW [1]. The obstacle that hampers Indonesian wind energy extraction is due to its low wind speeds, which are $1.3-6.5 \mathrm{~m} / \mathrm{s}$ [2]. These unique wind characteristics urge Indonesia to make some innovations so that this low speed wind energy can be extracted.

Variable speed wind turbine technology has used low speed permanent magnet synchronous generator to avoid gearbox usage (Fig.1). This system was called direct drive wind turbine. Gearbox usage is unwanted because it costs additional mechanical losses to wind turbine and needs routine maintenance. Based on a research, it is found that gearbox is the most critical component in wind turbine system due to its high failure time compared to other components (20\% from total wind turbine failure time) [3].

Various type of generator has been developed for wind turbine application. Since the axial flux permanent magnet (AFPM) synchronous generator has compact structure and high power density [4], it is commonly used as one of the most popular types in direct drive wind turbine system

Generator parameters identification would be able to determine the generator operating point. Parameters of a generator are determined by predicting the back-EMF profile and generator inductance. In previous research, the EMF profile parameters of slot less AFPM generator has been successfully identified [5]. In this paper, an analytical model of AFPM generator will be developed to predict its inductance using Quasi-3D method. Predicted result with analytical method will be compared with experimental results. An Axial flux generator with single-sided slot less machine topology has been examined in this research.

\section{Inductance of Slotless AFPM Generator}

In synchronous generator, inductance term is used to represent voltage drop in loaded condition. In (Fig.2) voltage drop in generator caused by stator resistor and synchronous reactance is shown.

Received: August 20, 2009. Accepted: October 20, 2009 
Saliency effect for surface mounted AFPM generator can be ignored [6], so that direct and quadrature reactance have the same value. Synchronous reactance in synchronous generator can be classified as: magnetizing reactance and leakage reactance.

$$
X_{s}=X_{m}+X_{l s}
$$

\section{A. Magnetizing Inductance}

Magnetizing Inductance is used to represent mechanical to electrical energy conversion or vice versa. Magnetizing inductance is caused by rotor-stator and stator-stator mutual flux. Its value depends on value of effective air gap flux density.

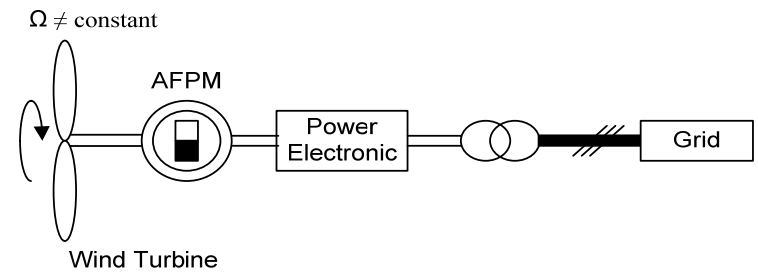

Fig. 1 Direct-drive wind turbine system

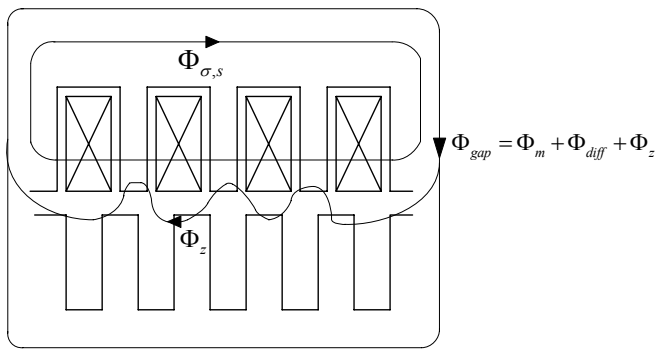

Fig. 2 Illustration of stator leakage flux path

\section{B. Leakage Inductance}

Leakage inductance in generator represents leakage flux which is not participating in electromechanical energy conversion. There are several types of leakage inductance: (i) differential leakage inductance, (ii) zigzag leakage inductance, (iii) skew leakage inductance, (iv) slot leakage inductance, (v) end-winding leakage inductance (Fig. 2) [7].

Not all air gap fluxes will be utilized in electromechanical energy conversion. Since higher harmonics are orthogonal to each other, and there is no magnetic coupling between them and fundamental. The higher spatial harmonic fluxes, which linked to conductors on the other side of the air gap travel at different speed than the fundamental flux. When there is no magnetic coupling between two fluxes, each of them is, for the other, a leakage flux. This leakage flux is called the differential flux leakage. Depending on the ratio between the slot opening and air gap width, there is a part of leakage flux which is called zigzag leakage flux. This leakage flux goes back to the iron without linking the conductors on the other side of the of the air gap. Flux leakage will occur, in a skewed permanent magnet rotor. This leakage is called skew leakage flux.

At the stator, leakage inductance is used to represent the flux resulted by the current flow at stator conductor. Slot leakage inductance represents flux generated by current in active side of conductor, which later connects the conductor and passes tangentially through the slot. While 
the end-winding leakage inductance represents the leakage flux developed by the current passing through the conducting wire at the end of winding.

Generator observed here, is the axial flux permanent magnet slot less generator. For slot less machine, the zigzag leakage inductance does not appear since there are no teeth in the stator. Differential leakage inductance may also be neglected since in spotless machine air gap flux density has sinusoidal profile, so that harmonic components can be neglected. There is also no skew leakage inductance, since the permanent magnet in the rotor; is not skewed

Magnetizing inductance, slot and end winding leakage inductance were calculated with electromagnetic field theory using Quasi-3D Method.

\section{Quasi-3D Method}

Analytical approach has been developed since the first electric machine was built and before computer-aided calculation, method was introduced. One of the most popular numeric calculations is finite element-3D which offers accurate because every part of machine can be modeled precisely by using mesh [8].

The main idea of quasi-3D method is dividing AFPM generator geometry into several computation sections then it is transformed into 2D geometrical shape. Magnetic field characteristic is analyzed in 2D geometrical shape model in order to obtain inductance value in each computation section. Finally, inductance values from all section are summed to get total value of generator inductance in stator winding.

In quasi-3D model, AFPM generator can be considered to be composed of several axialflux machines with differential radial length (Fig.3). Calculation of magnetic field characteristic in one computation section is done in computation radius which is determined by:

$$
R_{\text {comp }, i}=R_{\text {out }}-\frac{j \cdot l_{s}}{2 N}
$$

With $i$ is number of computation section, $j=2 .(i-1)+1, R_{\text {comp, }}$ is computation radius for $i^{\text {th }}$ computation section. In addition, $l_{\mathrm{s}}$ is the effective length of permanent magnet. While $1_{\mathrm{s}}$ value is defined as:

$$
l_{s}=\mathrm{R}_{\text {out }}-\mathrm{R}_{\text {in }}
$$

Computation length for each computation section is:

$$
l_{\text {comp }}=\frac{l_{s}}{N}
$$

\section{Inductance Calculation}

Inductance value is obtained by solving flux linkage equation due to current that caused it. Flux linkage is derived from the integral of flux density in a surface area. The inductance calculation is done by using magneto static field theory, and all time dependent variables were neglected. Materials in AFPM generator can be assumed as homogeny, linier and isotropic. In magneto static problem, we can use ampere's integral law and gauss' law in differential form.

Knowing potential vector equation will help to define value of other magneto static field equation variables such as flux density, flux linkage and inductance easily.

\section{A. Calculation of Magnetizing Inductance}

To predict flux density distribution in air gap, leakage coefficient of magnet permanent should be calculated first. In surface mounted AFPM generator, leakage flux in permanent magnet has a significant effect to total effective flux linkage reduction in air gap. 


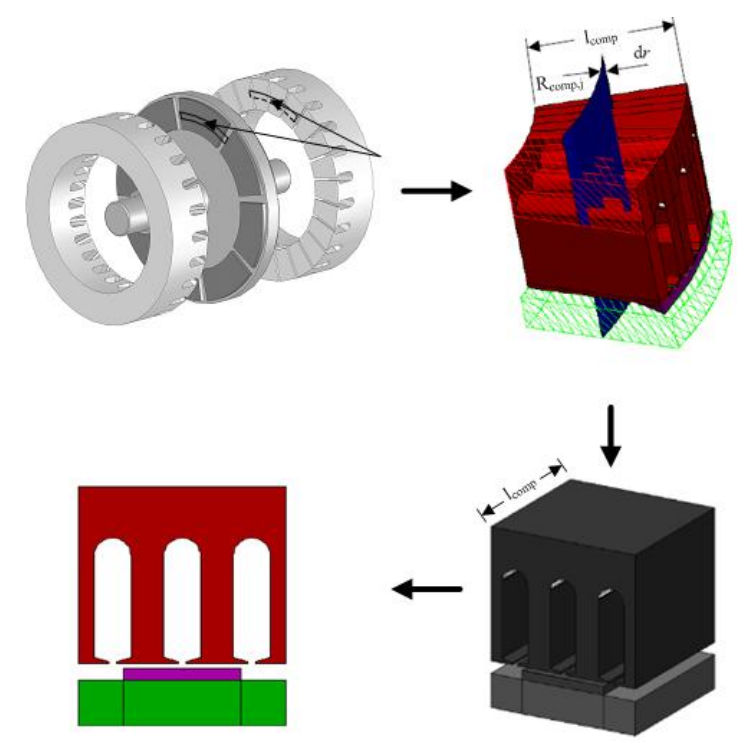

Fig. $33 \mathrm{D}$ to $2 \mathrm{D}$ transformation of quasi-3D Method

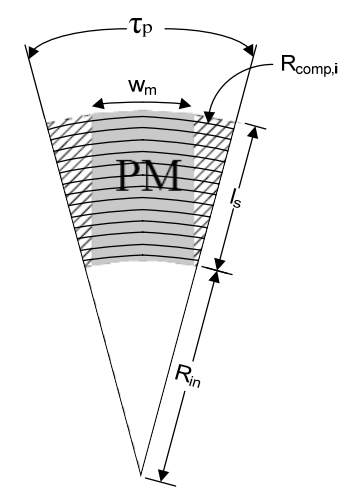

Fig. 4 Computation Radius of each Computation Section

$\nabla \times \mathbf{H}=\mathbf{J}$

$$
\nabla . \mathbf{B}=0
$$

Equation (5) and (6) can be solved directly or by using potential function. However, Maxwell equation usually solved using potential function. Vector potential is used to simplify the solution of magneto static field equation.

Leakage air gap flux in single-sided slot less AFPM generator as a function of its geometry was calculated by [5]:

$$
k_{\text {leak, agap }}=\frac{1}{1+\frac{2 \cdot g_{e f f}}{\pi \cdot\left(w_{m}+2 g_{e f f}\right)} \cdot\left(\ln \left(1+\frac{\pi \cdot \min \left[w_{f} / 2, w_{m} / 2, g_{e f f}\right]}{h_{m}}\right)+2 \cdot \ln \left(1+\frac{\pi \cdot w_{m}}{2 w_{f}}\right)\right)}
$$


Magnetizing inductance calculation is done in each computation section, started with looking for potential vector in air gap. To obtain expected vector potential, flux density distribution, which is caused by displacement current of permanent magnet, and boundary condition of each computation area should be determined first. By using potential vector, flux density in $y$-axis direction then can be determined. Based on previous research [5], air gap flux density in single-sided slot less AFPM generator can be calculated by:

$$
B_{g a p, n s}(x, y)=\sum_{n=1,3, \ldots}^{\infty} \frac{0.5 \alpha_{n}\left(1-p^{2}\right)\left(q^{2} \cdot e^{\alpha_{n n} y}+e^{-\alpha_{n y}}\right)}{\left(q^{2}-1\right) p} A z n \cdot \cos \left(\alpha_{n} x\right)
$$

And

$$
\begin{aligned}
& \alpha_{n}=\frac{\pi n}{\tau_{p}} \\
& p=\mathrm{e}^{-\alpha_{n} h m} \\
& q=\mathrm{e}^{-\alpha_{n} h g} \\
& A z n=\frac{-4 \mu_{o} H c}{\alpha_{n}{ }^{2} \tau_{p}} \sin \left(\frac{\alpha_{n} w_{m}}{2}\right)
\end{aligned}
$$

$H_{c}$ is permanent magnet coersivity, and $\tau_{p}$ is pole-pitch width. It can be seen significantly that flux density equation is a function of generator geometry.

In slot less AFPM Generator, stator winding was located it air gap (air cored winding). This condition causes each layer of stator winding is influenced by different value of flux density depend on its height in x-axis direction. In other words, a phase winding which has $\mathrm{N}_{\text {lay }}$ winding layer will get different value of flux linkage in each winding layer.

In this topology, flux linkage in each winding layer is derived from effective flux density which exists in air gap as a function of height. This effective flux linkage can be calculated using:

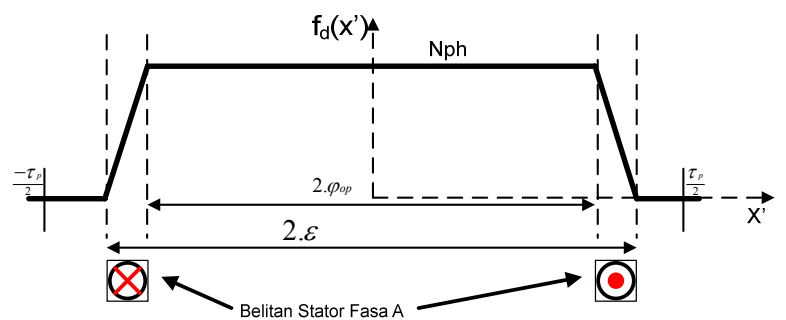

Fig. 5 Winding Distribution Function of Stator Winding Structure

$$
\begin{aligned}
& \Phi_{j, g, \text { eff }}=k_{\text {leak }, \text { agap } .} \Phi_{j, m} \\
& \Phi_{j, m}=\int_{0}^{l_{\text {coomp }}} \int_{-\tau_{p} / 2}^{\tau_{p} / 2} B_{j, g a p, n s}\left(x^{\prime}-v \cdot t, y_{j}\right) \cdot d x^{\prime} \cdot d l
\end{aligned}
$$


If winding distribution function $f_{d}\left(x^{\prime}\right)$ is used:

$f_{d}(x)=\sum_{n=1,3, \ldots}^{\infty} \frac{4 N_{p h} \tau_{p}\left(\cos \left(\alpha_{n . \varepsilon}\right)-\cos \left(\alpha_{n .} \varphi_{o p}\right)\right)}{(n \pi)^{2}\left(\varphi_{o p}-\varepsilon\right)} \cos \left(\alpha_{n . x}\right)$

By changing its maximum winding value with $\mathrm{N}_{\text {turn/lay }}$ and function $B_{j, g a p, n s}\left(x^{\prime}-v . t, y_{j}\right)$ as in equation (8), then equation (14) can be solved to:

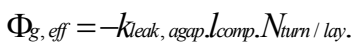

$$
\sum_{j=1}^{N a v n} \sum_{n=1,3, \ldots}^{\infty} \frac{\left(\cos \left(\varphi_{o p} \cdot \alpha_{n}\right)-\cos \left(\varepsilon \cdot \alpha_{n}\right)\right)\left(1-p^{2}\right)\left(q^{2} \cdot e^{\alpha_{n y j}}+e^{-\alpha_{n n j}}\right)}{\alpha_{n}\left(\varphi_{o p}-\varepsilon\right)\left(q^{2}-1\right) p}
$$

With

$v=\omega \cdot R_{\text {calc }}$

$\omega=$ Angular speed $(\mathrm{rad} / \mathrm{s})$

And,

$N_{\text {lay }}=\left\lfloor\frac{\text { hcoil }}{d_{\text {wire }}}\right\rfloor$

hcoil $=$ winding height

$d_{\text {wire }}=$ wire diameter

$N_{\text {turn / lay }}=\frac{N_{\text {ph }}}{N_{\text {lay }}}$

$y_{j}=h g-j \cdot \frac{d_{\text {wire }}}{2}$

$\mathrm{j}=1,3, \ldots, 2 .\left(N_{\text {lay }}-1\right)+1$

Permanent magnet can be assumed as an equivalent current density distribution. Current distribution which is caused by permanent magnet in AFPM generator is shown by equation (20) [5]. Integrating it by surface, equivalent current can be obtained.

$$
\begin{aligned}
& \mathbf{J}=-\sum_{n=1,3,5, \ldots}^{\infty} \frac{4 H c}{\tau_{p}} \sin \left(\frac{\alpha_{n} w_{m}}{2}\right) \sin \left(\alpha_{n} x\right) \mathbf{a} z \\
& I=\int_{s} J . d s
\end{aligned}
$$

Solution of flux linkage for entire winding can be obtained by summing all flux linkage which is derived from each computation section. Dividing this total fluxes linkage by equivalent rotor current will give Magnetizing inductance value. 


\section{B. Calculation of Leakage Inductance}

Slot and end-winding leakage was calculated by using electromagnetic field theory which is applied through quasi 3D method.

For thin wire, $\mathrm{J} d v^{\prime} \rightarrow \mathrm{I} d l$, in free space $\left(\mu=\mu_{0}\right)$ which is homogeny, linear and isotropic, vector potential equation can be determined by [9],[10]:

$$
\mathbf{A}(\mathrm{x})=\frac{\mu_{0} I}{4 \pi} \int_{\mathrm{c}} \frac{d \mathrm{l}^{\prime}}{\left|\mathrm{x}-\mathrm{x}^{\prime}\right|^{\prime}}
$$

Where

$\mathrm{A}(\mathrm{x})=$ Vector potential as distance function

$\left|\mathrm{X}-\mathrm{X}^{\prime}\right|=$ Distance of observed point to source

Current flows in conductor so that integral $d l$ in each computation section is computation section length $\left(l_{c}\right)$. If distance between source and observed point is $r$, assuming current flow in z-axis, therefore flux density caused by current flowed in wire conductor along $l_{c}$ can be obtained by:

$$
B=\nabla \times A=\left(\begin{array}{ccc}
\frac{\vec{a}_{r}}{r^{2} \sin \theta} & \frac{\vec{a}_{\theta}}{r \sin \theta} & \frac{\vec{a}_{\phi}}{r} \\
\frac{\partial}{\partial r} & \frac{\partial}{\partial \theta} & \frac{\partial}{\partial \phi} \\
A r & r A_{\theta} & r \sin \theta A_{\phi}
\end{array}\right)
$$

That,

$$
\begin{aligned}
& A_{r}=A_{z} \cos \theta \\
& A_{\theta}=-A_{z} \sin \theta \\
& A_{\phi}=0
\end{aligned}
$$

By changing the potential vector variable in equation (23) with vector potential vector in equation (24) and (22), then:

$$
\mathrm{dB}(\mathrm{r})=\frac{\mu_{0} I d l_{c}}{4 \pi r^{2}} \sin \theta \vec{a}_{\phi}
$$
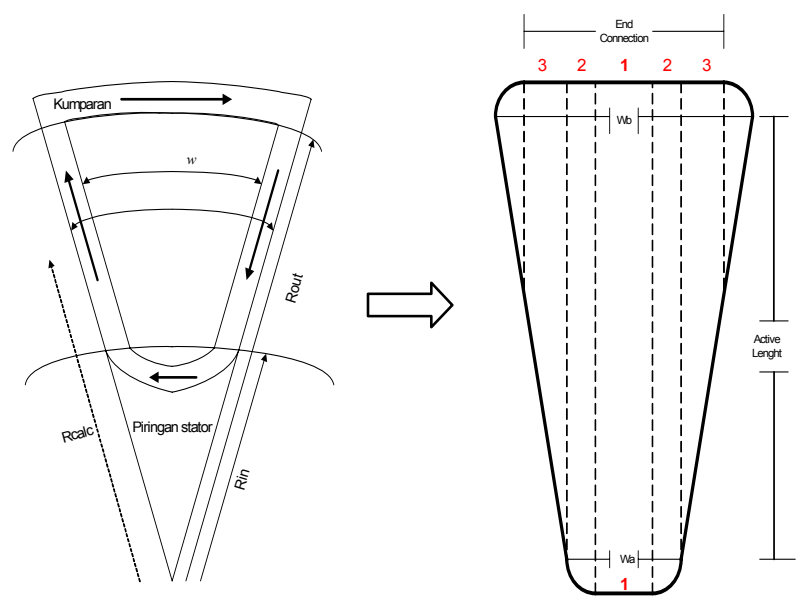

Fig. 6 Region Division for Calculation of Stator Leakage Inductance 
Then flux linkage for each computation section can be derived by integrating flux density in its computation section.

$\Phi_{j}=\int_{\frac{D}{2}}^{w-\frac{D}{2}} \int_{\frac{-l_{c}}{2}}^{\frac{l c}{2}} d B_{j}(r) d l \cdot d r$

$\Phi_{\mathrm{j}}=$ flux linkage for each computation section

$\mathrm{B}_{\mathrm{j}}=$ flux density in each computation section

$\mathrm{w}=$ width of observed winding

$\mathrm{D}=$ conductor diameter

Refers to winding geometry (Fig 5), equation (25) and (26), then by dividing flux linkage by conductor current which causes it, leakage inductance can be calculated by equation:

$L_{l-\ldots}=\sum_{j=1}^{N_{c o m p}} \sum_{i=1}^{N_{x}} \frac{\mu_{0}(D-W)}{\pi D(D-2 W)} l_{c o m p}$

Calculation area then divided into 4 regions. Moreover, by using quasi 3D method, slot less AFPM generator leakage inductance can be specified as:

Slot leakage inductance calculation in active region

$$
L_{l-\text { slot }}=\frac{2 \mu_{0} l_{\text {comp }}}{\pi D} \sum_{j=1}^{N_{\text {comp }}} \sum_{i=1}^{N_{y}} \frac{2 D(1-i)-W a+(1-j) \frac{(W b-W a)}{\left(N_{\text {comp }}-1\right)}}{D(3-4 i)-2 W a+2(1-j) \frac{(W b-W a)}{\left(N_{\text {comp }}-1\right)}}
$$

Leakage inductance in end winding region - 1

$$
L_{l-\text { end }-1}=\frac{2 \mu_{0} l_{\text {comp }}}{\pi D} \sum_{j=1}^{N_{\text {comp }}} \sum_{i=1}^{N_{x}} \frac{2 D(1-i)-l_{\text {act }}-2 r_{\text {sudut }}}{D(3-4 i)-2 l_{\text {act }}-4 r_{\text {sudut }}}
$$

Leakage inductance in end winding region - 2

$$
L_{l-\text { end }-3}=\frac{\mu_{0} l_{\text {comp }}}{2 \pi D} \sum_{j=1}^{N_{\text {comp }}} \sum_{i=1}^{N_{x}} \frac{D\left(\frac{3}{2}-i\right)-l_{\text {act }}-r_{\text {sudut }}-s_{\text {sudut }}}{D(1-i)-l_{\text {act }}-r_{\text {sudut }}-S_{\text {sudut }}}
$$

Leakage inductance in end winding region - 3

$$
L_{l-\text { end }-3}=\frac{\mu_{0} l_{\text {comp }}}{\pi D} \sum_{j=1}^{N_{\text {comp }}} \sum_{i=1}^{N_{y}} \frac{2 D(1-i)-r_{\text {sudut }}+(1-j) \frac{\left(l_{\text {cat }}+r_{\text {sudut }}\right)}{\left(N_{\text {comp }}-1\right)}}{D(3-4 i)-2 r_{\text {sudut }}+2(1-j) \frac{\left(l_{\text {cct }}+r_{\text {sudut }}\right)}{\left(N_{\text {comp }}-1\right)}}
$$

End winding leakage inductance in corner of winding can be neglected due to its small corner diameter. Therefore, arc length in corner of winding is much smaller than other conductor length. 


\section{AFPM Generator Frequency Response Test}

To validate proposed quasi-3D method, an experiment to obtain actual slot less AFPM generator inductance by frequency response test is performed. The generator has geometry parameters as follow:

TABLE 1

DIMENSION PARAMETER OF OBSERVED AFPM GENERATOR

\begin{tabular}{|l|l|ll|}
\hline Parameter & Symbols & \multicolumn{3}{|l|}{ Quantities } \\
\hline Generator outer radius & $\mathrm{R}_{\text {out }}$ & 15 & $\mathrm{~cm}$ \\
\hline Generator inner radius & $\mathrm{R}_{\text {in }}$ & 9.8 & $\mathrm{~cm}$ \\
\hline Number of magnet & $2 . p$ & 16 & \\
\hline Magnet length & $\mathrm{I}_{\mathrm{m}}$ & 5.08 & $\mathrm{~cm}$ \\
\hline Magnet width & $\mathrm{W}_{\mathrm{m}}$ & 2.54 & $\mathrm{~cm}$ \\
\hline Magnet depth & $\mathrm{Hm}$ & 1.27 & $\mathrm{~cm}$ \\
\hline Air gap & $\mathrm{g}_{\mathrm{ac}}$ & 1.32 & $\mathrm{~cm}$ \\
\hline Rotor disk height & $\mathrm{h}_{\mathrm{r}}$ & 1.2 & $\mathrm{~cm}$ \\
\hline Stator disk height & $\mathrm{h}_{\mathrm{s}}$ & 1.2 & $\mathrm{~cm}$ \\
\hline Winding height & $\mathrm{h}_{\text {coil }}$ & 1.3 & $\mathrm{~cm}$ \\
\hline Wire Diameter & $\mathrm{d}_{\text {wire }}$ & 0.9 & $\mathrm{~mm}$ \\
\hline turn/phase & $\mathrm{N}_{\text {ph }}$ & 800 & $\mathrm{turn}$ \\
\hline winding/phase & & 4 & \\
\hline Number of phase & $\mathrm{m}$ & 3 & \\
\hline Coersivity & $\mathrm{H}_{\mathrm{c}}$ & 979000 & $\mathrm{~A} / \mathrm{m}$ \\
\hline Winding width & $\Sigma$ & 1.7 & $\mathrm{~cm}$ \\
\hline
\end{tabular}

The main idea of frequency response test is to observe any change on impedance value when generator is injected with current in various frequencies. Notice Fig. 7, if generator is injected with high frequency current, then magnetizing reactance value $\left(X_{m}=2 \pi f . L_{m}\right)$ will be much greater than rotor resistance value $\left(R_{r}\right)$. The current which flows through Magnetizing reactance is much smaller than the one that flows through rotor resistance. In addition, vice versa, for low frequency current injection, the magnetizing reactance will be much smaller than rotor resistance. It will allow us to identify the actual value of magnetizing and leakage inductance.

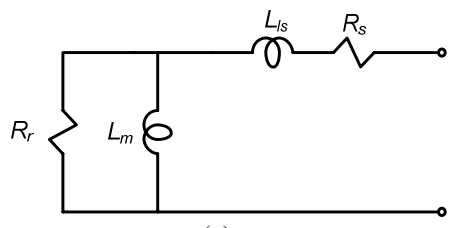

(a)
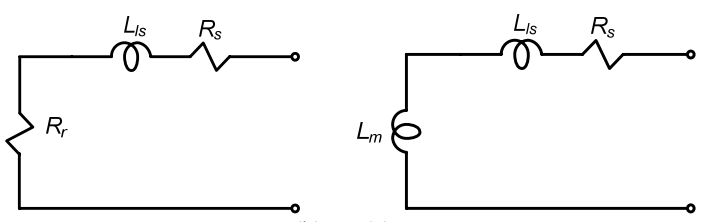

(b) (c)

Gb.7 (a) Equivalent circuit of AFPM generator (b) injected with high frequency current

(c) injected with low frequency current 


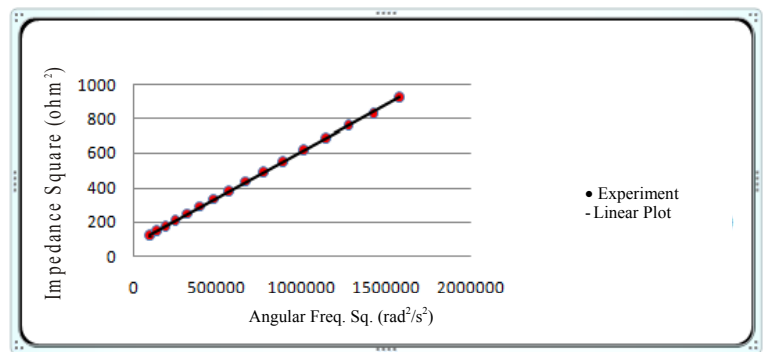

Fig.8 Relation of squared impedance and squared high angular frequency

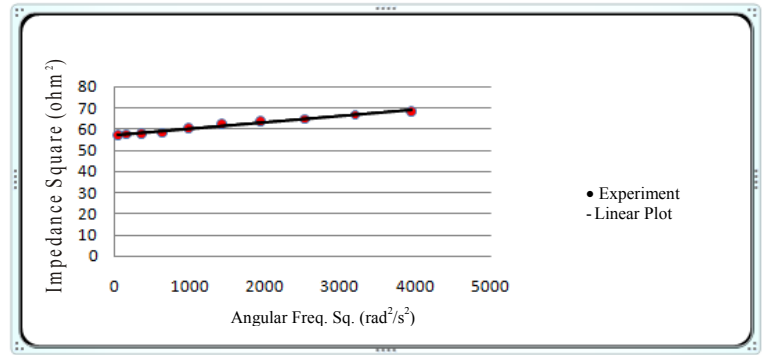

Fig.9 Relation of squared impedance and squared low angular frequency

Influence of skin effect on change of AC resistance that is caused by frequency change can be neglected, compared to its reactance change. Therefore, if linear area in low and high frequency are taken from relationship of squared impedance and squared angular frequency data, parameters $R_{e q}$ and $L_{e q}$ can be obtained. $L_{e q}$ is the gradient of the curve. $R_{e q}$ is obtained by extrapolating the curve to the zero point. Linear curve from relation of squared impedance and squared angular frequency obtained from experiment data in high frequency $(50-200 \mathrm{~Hz})$ (shown in Fig. 8), and low frequency (1-10 Hz) (shown in Fig. 9).

TABLE 2

COMPARISON BETWEEN ANALYTIC CALCULATION AND EXPERIMENT RESULT

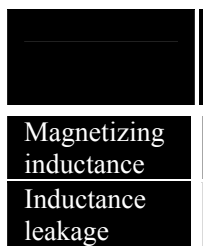

\begin{tabular}{|l|l|l|l|}
\hline Symbol & $\begin{array}{l}\text { Experiment } \\
\text { Result }\end{array}$ & $\begin{array}{l}\text { Analytic } \\
\text { Calculati } \\
\text { on }\end{array}$ & $\begin{array}{l}\text { Error } \\
(\%)\end{array}$ \\
\hline $\mathrm{L}_{\mathrm{s}}(\mathrm{mH})$ & 23.24 & 23.38 & 0.602 \\
\hline $\mathrm{L}_{\mathrm{m}}(\mathrm{mH})$ & 31.76 & 32.2 & 1.385 \\
\hline
\end{tabular}

By extrapolating curves in Fig 8 and Fig 9, the stator resistance $\left(R_{s}\right)$ was $7.56 \Omega$ and rotor resistance was $1.06 \Omega$. From table 2 , it is obvious that the difference of inductance calculations between analytic method and experiment is not significant.

\section{Conclusions}

From this research, these following were concluded:

Quasi-3D could be applied in calculation of AFPM slot less generator inductance with high accuracy. An experiment method has been proposed to measure inductance value of slot less AFPM generator. It is shown that proposed analytic method for preliminary design consumed less time. 


\section{References}

[1] Departemen ESDM,"Blueprint Pengelolaan Energi Nasional 2005-2025", Indonesia, 2005

[2] John M. Kusterer,'NASA Surface meteorology and Solar Energy: Global / Regional Data", http://eosweb.larc.nasa.gov, 2008.

[3] J. Ribrant, and L. Bertling,"Survey of failures in wind power systems with focus on Swedish wind power plants during 1997-2005”, IEEE Transactions on Energy Conversion. Vol 22, No. 1, March, 2007.

[4] J.F. Gieras, R.J. Wang, M.J. Kamper, “Axial Flux Permanent Magnet Brushless Machine", Kluwer Academic Publisher, Dordrecht, 2004.

[5] H.A. Wibowo, " Prediksi Profil Gaya Gerak Listrik pada Generator Sinkron Fluksi Aksial - Magnet Permanen" Tugas Akhir, Institut Teknologi Bandung, Indonesia, 2008.

[6] B. Klockl,"Measurement Based Parameter Determination of Permanent Magnet Synchronous Machine”, Diploma Thesis, Graz University of Technology, Austria, 2001.

[7] V. Ostovic, "Computer-Aided Analysis of Electric Machines", Prentice Hall, Cambridge, 1994.

[8] Nicola Bianchi, "Electrical Machine Analysis Using Finite Element", CRC Press Taylor \& Francis Group, Florida, 2004.

[9] M.F. Iskander, "Electromagnetic Fields and Waves", Waveland Press Inc., Illinois, 1992.

[10] E.P. Furlani, "Permanent Magnet and Electromechanical Devices", Academic Press, San Diego, 2001. 